\title{
Unilateral gynecomastia in a prepubertal boy
}

\author{
Florian Ensat • Monika Edelbauer • \\ Gottfried Wechselberger
}

Received: 11 July 2011 / Accepted: 26 July 2011 /Published online: 6 September 2011

(C) Springer-Verlag 2011

We report the case of a 12-year-old Caucasian boy with an enlarged left breast without significant skin excess. According to Simon [1] this is a grade I (Fig. 1). The boy, suffering from ADHD, had been treated since the age of 4 years with methylphenidate $(10 \mathrm{mg} /$ day $)$, a potent central nervous system stimulant and amphetamine derivative. At the age of 6 years, unilateral gynecomastia was diagnosed, with an ongoing progression causing an emotional burden. On physical examination, the left breast was enlarged without galactorrhea, nipple discharge, nipple retraction, lymphadenopathy, or skin changes. Palpation of the right breast did not show any conspicuous findings. Preoperative ultrasound showed diffuse nodular breast gland hypertrophy $(7 \times 5 \times 1 \mathrm{~cm})$ of low echogenity and dense stromal fibrosis with no evidence of microcalcification, or cyst formation. The boy underwent subcutaneous mastectomy through a semicircular inferior periareolar incision. (Fig. 2) Histological examination revealed a ductal and acinar breast epithelium with stroma, fibrosis, and glandular hyperplasia with no evidence of malignancy confirming the diagnosis as "true gynecomastia." The patient had an uneventful postoperative recovery. A 6-month follow-up showed no recurrence, and the right breast was still inconspicuous.

Further systematic studies are needed to analyze endocrine dysfunctions associated with methylphenidate treatment in young patients with ADHD.

F. Ensat $(\square) \cdot$ G. Wechselberger

Department of Plastic and Reconstructive Surgery,

Krankenhaus der Barmherzigen Brüder,

Teaching Hospital of the Paracelsus

Medical University Salzburg,

Kajetanerplatz 1,

5020 Salzburg, Austria

e-mail: florian.ensat@bbsalz.at

\section{Edelbauer}

Department of Paediatrics, Innsbruck Medical University, Innsbruck, Austria

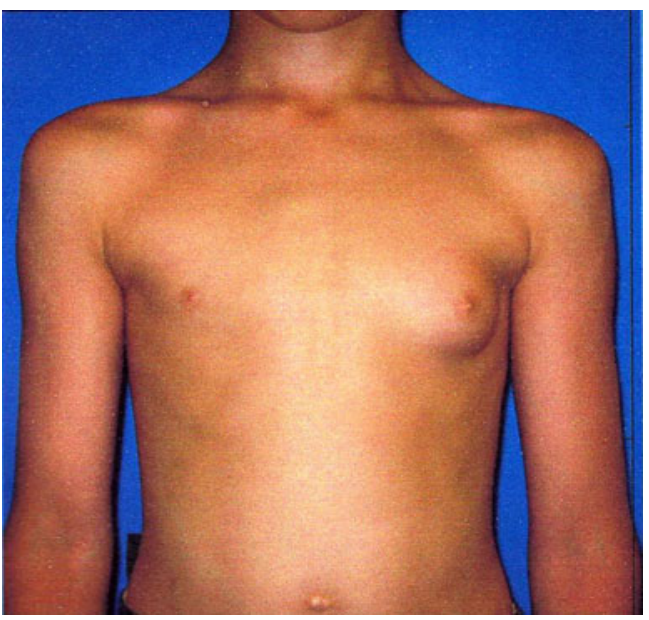

Fig. 1 Preoperative appearance of the boy with persistent unilateral gynecomastia

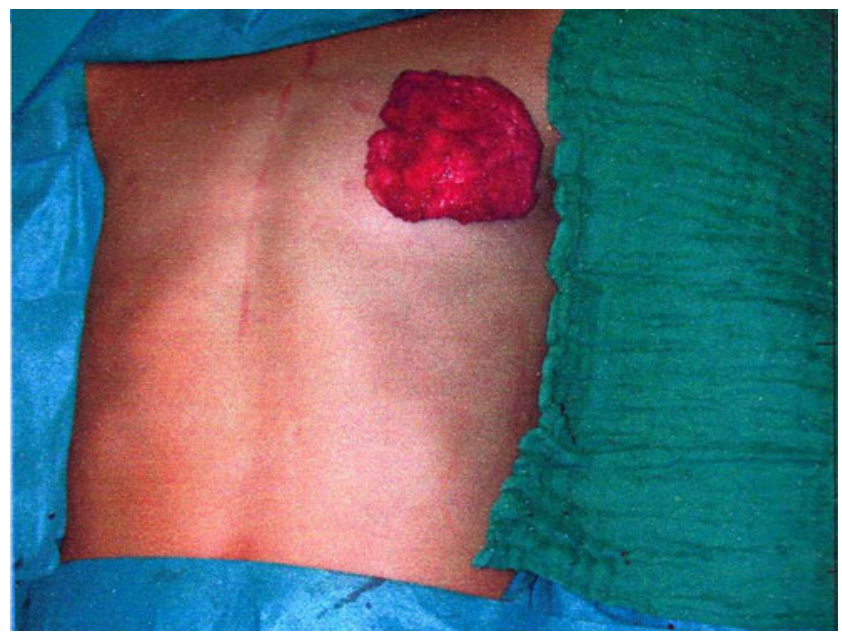

Fig. 2 Intraoperative appearance of removed fibroglandular breast tissue $(38,5 \mathrm{~g})$ using the inferior periareolar approach

\section{Reference}

1. Simon BE, Hoffman S, Kahn S (1973) Classification and surgical correction for gynecomastia. Plast Reconstr Surg 51:48 